\title{
Construction of a Sensitive Bisphenol A Electrochemical Sensor based on Metal-organic Framework/Graphene Composites
}

\author{
Congming $\mathrm{Li}^{1}$, Yanli Zhou ${ }^{1,2, *}, \mathrm{Xu} Z \mathrm{Zhu^{2 }}$, Baoxian $\mathrm{Ye}^{1}$, Maotian $\mathrm{X} \mathrm{u}^{1,2, *}$ \\ ${ }^{1}$ College of Chemistry and Molecular Engineering, Zhengzhou University, Zhengzhou 450001, \\ China \\ ${ }^{2}$ Henan Key Laboratory of Biomolecular Recognition and Sensing, Shangqiu Normal University, \\ College of Chemistry and Chemical Engineering, Shangqiu 476000, China \\ *E-mail: zhouyanli@ mails.ucas.ac.cn (Y.Zhou); xumaotian@sqnu.edu.cn (M. Xu).
}

doi: $10.20964 / 2018.05 .52$

Received: 24 January 2018 / Accepted: 8 March 2018 / Published: 10 April 2018

\begin{abstract}
Bisphenol A (BPA), as a typical endocrine disruptor, has caused widespread concern in recent years, and its sensitive detection is particularly important. In this study, a sensitive BPA electrochemical sensor was fabricated using composites of copper-based metal-organic frameworks (Cu-MOFs) and electrochemically reduced graphene oxide (ERGO). The Cu-MOFs, ERGO, and Cu-MOFs/ERGO were characterized by scanning electron microscopy. Compared with the Cu-MOFs- or ERGOmodified electrode, the $\mathrm{Cu}-\mathrm{MOF} / \mathrm{ERGO}$-modified electrode displayed significantly enhanced electrocatalytic activity toward BPA. The prepared electrode displayed linear range from $0.02 \mu \mathrm{M}$ to $90 \mu \mathrm{M}$ and limit of detection of $6.7 \mathrm{nM}(\mathrm{S} / \mathrm{N}=3)$ for BPA detection as shown by differential pulse voltammetry results under optimized conditions. Such good sensitivity could be ascribed to the synergistic catalysis from high adsorption and catalytic capacity of $\mathrm{Cu}-\mathrm{MOF}$ and to the excellent conductive property of ERGO. The $\mathrm{Cu}-\mathrm{MOF}$ /ERGO-modified electrode also exhibited high stability and anti-interference ability. The proposed sensor was successfully applied to determine BPA in plastic products. Thus, a promising and reliable tool is provided for the rapid analysis of emergency pollution caused by BPA.
\end{abstract}

Keywords: Metal organic framework; Graphene; Electrochemical sensor; Bisphenol A

\section{FULL TEXT}

(C) 2018 The Authors. Published by ESG (www.electrochemsci.org). This article is an open access article distributed under the terms and conditions of the Creative Commons Attribution license (http://creativecommons.org/licenses/by/4.0/). 